\title{
EL ÁRABE /KANĪSA/ 'IGLESIA' EN LA TOPONIMIA ESPAÑOLA
}

\author{
Leopoldo Peñarroja Torrejón
}

1. Las fuentes árabes medievales hacen uso del término /kanīsa/ (raramente del árabe / $\mathrm{bi}^{\prime} \mathrm{a} /$ ) para aludir a una iglesia cristiana, ya de los reinos del norte, hispánicos o extrahispánicos, ya de la población mozárabe de AlAndalus ${ }^{1}$. Las transliteraciones latinas del generalizado / kanīsa/ difieren poco y conservan un ductus consonántico k.n.s. Esto es lo que todos aceptábamos hasta que recientemente se ha discutido el sentido de los derivados de / kanīsa/ en la toponimia española ${ }^{2}$. Como, por fortuna, son bastantes los materiales que resuelven esta duda, me ocuparé aquí de fijar el sentido de este arabismo, verificar su uso en las fuentes hispanoárabes y señalar sus continuaciones en la toponimia hispánica.

2. Ya R. Chabás ${ }^{3}$, J. Sanchis Sivera ${ }^{4}$ y R. Menéndez Pidal ${ }^{5}$ notaron la presencia de derivados de / kanīsa/ en territorio valenciano. Luego,

1 La alternancia de formas en E. Lévi-Provençal, España Musulmana hasta la caída del Califato de Córdoba, en Historia de España, dir. por R. Menéndez Pidal, V, Madrid, 1957, pág. 125.

2 Aludo a Mikel de Epalza, paladín de una arriesgada postura que, contra la evidencia de las fuentes históricas, niega la existencia de comunidades cristianas autóctonas (mozárabes) en la España Musulmana [sobre todo en «¿¿Hubo mozárabes en tierras valencianas? Proceso de islamización del Levante de la Península (Shark-al-Andalus)», Revista del Instituto de Estudios Alicantinos, 36, 1982, págs. 17-27]; y que, a propósito del topónimo Alquenicia, afirma tener «un àmbit geografic d'utilitzacio molt més ample que no pas la Peninsula Ibèrica [...] la seva càrrega semàntica es molt més ampla que la d'esglesia cristiana: es també sinagoga jueva, temple antic $\mathrm{i}-$ crec que es molt important per als toponims valencians- cementeri pre-islamic» (Caplletra 1 [Valencia, 1985], pág. 104). A la falta de apoyos de tal hipótesis me refiero en Cristianos bajo el Islam. Los mozárabes hasta la reconquista de Valencia, Madrid, Gredos (en prensa), § 1, n. 20.

3 Roque Chabás, Episcopologio Valentino, Valencia, 1909, pág. 215.

- José Sanchis Sivera, La Diócesis Valentina, Valencia, 1921, pág. 148.

- Infra. 
M. Sanchis Guarner ${ }^{6}$ los recogió al lado de varios nombres geográficos de Mallorca y Cataluña ${ }^{7}$. Antonio Ubieto se ha referido a ellos ${ }^{8}$; y yo mismo he agr ‘gado varios de estos topónimos a la nómina de los consabidos 9 .

3. C. Van Arendonk ${ }^{10}$ atribuye al árabe /kanīsa/ $<$ arameo $/ \mathrm{k}^{\mathrm{e}}$ nīśtā/) dos diferentes sentidos: 'sinagoga' e 'iglesia'. Para Al-Hafāğĩ ", en cambio, la denotación específica de esta voz es la de una institución cristiana; y Al-Bustānī ${ }^{12}$, ve en ella una continuación del griego é $\times \times \lambda \gamma$ r $\sigma i \alpha^{13}$. De hecho, /kanisa/ concurre en los textos árabes con los significados de 'lugar de culto, judio o cristiano' ${ }^{14}$. Pero con una importante restricción: los textos hispanoárabes y los relativos a la España musulmana emplean / kanīsa/ con un único (o al menos enteramente general) sentido 'iglesia cristiana'. No hay otra divergencia que las matizaciones dialectales señaladas por J. Samsó ${ }^{15}$ : /kinisya/ en Andalucia; /kanásya/ en la Región Valenciana y en Baleares; /kanisya/ en la misma Valencia y en Aragón.

\section{/KANĪSA/ EN LA TOPONIMIA ESPAÑOLA}

4. He aquí una relación de topónimos hispánicos derivados de / kanīsa/: en Andalucía, Quinicia (en la Vega de Granada), identificable con el $\mathrm{Al}$ Qanays de Al-'Udrī ${ }^{16}$; Quinizen o Al-Quinizen (Granada) ${ }^{17}$; Quinicia Tal$m e</$ kanīsat al-mā/ ('iglesia del agua') o quizá /kanīsat al-mal/ ('iglesia

6 Manuel Sanchis Guarner, «Las minorías religiosas en la toponimia de Cataluña, Valencia y Mallorca», Acta Salmanticensia 11/1, Salamanca, 1958, págs. 467-473.

7 /kanisa/ de Alcira, Alicante, L'Orcha, Murla y Novelda.

8 Antonio Ubieto, Origenes del Reino de Valencia, Valencia, 1975, 122/9.

- Leopoldo Peñarroja Torrejón, Moriscos y repobladores en el Reino de Valencia: La Vall d’Uxó (1525-1625), Valencia, 1984, I, 127 y II, doc. 8, asiento 204, pág. 556.

10 C. Van Arendonk, «Kanisa», Shorter Encyclopaedia of Islam Leiden, 1974, 216ab.

11 Al-Hafäŭĩi, Sifa' al-ḡalìl, Cairo, 1282 hég., pág. 195.

12 Al-Bustãni, Muhił al-Muhìt, Beirut, 1286 hég., 1847.

13 Federico Corriente propone una base aramea / kanisa/, común a dialectos de la población judía y cristiana, así al talmúdico y arameo cristiano-palestinense. Cfr. F. Co rriente, "Anotaciones al margen de kanisi(y)a y mezquita», Al-Andalus 43, 1978, págs. 221224, especialmente 221-222. Además R. Dozy, Supplément aux dictionnaires arabes, s/v.

14 Ad casum, Al-Gawharī, Saḥah, Būlāq, 1282 hég., I, 473; Zamab̧šarī, Asâs al. Baldğa, Cairo, 1299 hég., II, 212, etc.

1s J. Samsó, «Sobre la voz/kanisa/ en el haz dialectal hispano-árabe», Al-Andalus 43, 1978, págs. 209-221.

16 Luis Seco de Lucena, «Toponimia árabe de la Vega y los montes de Granada», Al-Andalus 29, 1964; Al-'Ud̆rī, Nușūs an al-Andalus (fragmentos de su Kitâb tarsi' al-abbar wa-taniwi' [...], ed. de 'Abd al-'Azīz Al-Ahwãni [Madrid, 1965], 90).

17 Cfr. M. C. Villanueva, Habices de las mezquitas de la ciudad de Granada y sus alquerias, Madrid, 1961, págs. 341, 363. 
del tesoro') (Sevilla) ${ }^{18}$; Alquinecia (en Comares, prov. de Málaga) ${ }^{19}$; Gáabl al-Qunaysa ('monte de la iglesuela'), ahora en provincia de Almeria, en textos de Ibn al-Hātima [muerto hacia 1369] ${ }^{20}$.

5. En Baleares, Ses Canessies, nombre de una alqueria y un barranco en el término de Migjorn Gran (Menorca), donde, significativamente, se hallaron en 1951 las ruinas de una basílica paleocristiana ${ }^{21}$; Alconàsser (Mallorca) ${ }^{22}$; Alcaneyz y Alcaneys (< pl. /al-kanāyis/), s. xiII ${ }^{23}$.

6. En Cataluña hay Conesa < /qunaysa/ ('la iglesuela'), en la provincia de Tarragona (comarca de la Conca de Barberà). Alcanyiset, en Lérida, exige mejor canni ci u $+-\overline{i t t u}$ que /kanisa/. Pero existe la hibridación Avacanicelas, donde / kanīsa/ + - ěl1 a s = 'iglesuelas', según figura en la delimitación de términos de Lérida, mediados del siglo xil, copiada en el Llibre Vert Petit:

Et turres d'Aviniuniç et d'Ovacariça et d'Avacaniçelas e dels Quadros et d'Abalachin et de Morçillon et de las Molas [...] ${ }^{24}$.

7. En Aragón subsisten dos Alcañiz (uno en la prov. de Teruel y otro en término de Toscos, partido judicial de Cariñena, prov. de Zaragoza), que podrían remontar a un cannīciu 'cañaveral'; aunque venga en favor de / kanīsa/ la documentación más antigua, que alterna Alcaniz / Alcanicia / Alcanicha / Alcanniz / Alkanic / Alkanniz, desde 1124 ${ }^{25}$. (Asín lo supone un plural 'las iglesias' ${ }^{26}$ ). Y un Alcañicejo, prov. de Zaragoza ${ }^{27}$.

8. Para Castilla y León se recogen Alconeza (prov. de Soria), Alcuneza (Guadalajara), Alcañices (Zamora) y Alcañizo (Toledo).

9. Los derivados de /kanisa/ son particularmente abundantes en la región de Valencia. L'Alquenensia, partida rural de Alcira, en la Ribera del

18 Julio González, Repartimiento de Sevilla, Madrid, 1961, II, págs. 111 y 118.

19 Bejarano Robles y Vallvé Bermejo, Repartimiento de Comares, Barcelona, 1974, pág. 11 .

${ }_{20}$ Leopoldo Torres Balbás, «Mozarabías y juderías en las ciudades hispanomusulmanas», Al-Andalus 19, 1954, pág. 187.

21 G. Seguí Vidal, «La basílica paleocristiana de Son Bou», Butlletí de la Societat Arqueologica Lul.liana 30, pág. 692; y M. Sanchis Guarner, loc. cit., pág. 469.

${ }_{22}$ J. Mascaró Pasaríus, Corpus de Toponimia de Mallorca, I, Palma, 1962, pág. 17.

23 Archivo Histórico de Mallorca, Protocolo 361, fol. 120. Apud. J. Samsó, ibid., pág. 214.

24 Archivo Municipal de Lérida, Llibre Vert Petit, fol. 145 rto.

25 Cfr. Agustín Ubieto Arteta, Toponimia aragonesa medieval, Valencia, 1972, pág. 25.

28 M. Asín Palacios, Contribución a la Toponimia Arabe de España, Madrid, 1941, pág. 52.

${ }_{27}$ Puede no ser una continuación de / kanisa/. -k'l- $>[\mathrm{x}]$ es solución castellana. 
Júcar, se transcribe en el Llibre del Repartiment Alcanicia, Alchannicia, Alcannicia ${ }^{28}$, en donaciones de 1242 . Al-Himyarī ${ }^{29}$ trae en su Kitäb ar-Razud un poema de Ibn-Hafağa [ $\dagger$ hacia 1138] ${ }^{30}$, que evoca con melancolia el lugar :

Laméntate de tu alejamiento de al-Marğ, de al-Kanisa y de as-Satt, y dite: ¡Ay de mí!, ¿quién hará revivir el amor que tenía por estos lugares?

La Canessia se llamaba a un barranco de Alicante, hoy desaparecido. La Canessia es un despoblado de L'Orcha, en el Valle de Perpunchent, Sierra de Benicadell (prov. de Alicante). Otro despoblado de Murla, en el Valle de Pop (comarca de la Marina, prov. de Alicante), Alcanissia es también citado en el Repartiment, año $1249^{31}$ :

B. Zarocha [et alii], II iovatas in Ceylent, Merniça Benigela, Raalhabelhabar, Benalbacar, Alcanicia, Benilacruçi, alcheriis de (Calp) Pop et singulas domos.

Els Canissis son todavía un paraje rural de La Romana, en la Vall de Novelda (prov. de Alicante); La Quenencia, un despoblado de Turís, en la Vall d' Alcalá (prov. de Valencia). Y Alquenicia era una partida de la Vall d'Uxó (prov. de Castellón), nombre en uso entre la población morisca en $1535^{32}$.

Por último, en el diploma de 1098 por el que el Cid dota a la catedral de Valencia y a su obispo Jerôme, se alude, entre otros donadíos, a las

Villas de Alcanitja omnes, cum molendinis, et aqueductibus et cum cunctis pertinentibus $[\ldots]^{33}$.

cuya traducción es: "todas las villas de Alcanicia, con los molinos, acequias y todas sus pertenencias". No han de identificarse (dudó ya al hacerlo $\mathrm{Me}-$

28 Transcripción de Desamparados Cabanes Pecourt y Ramón Ferrer Navarro, Zaragoza, I y II: 1979; III: 1980; vol. II, págs. 191, 213, 215, 224, 895, 900, 902, 913, 943 , 953, 962, 968, 972.

29 Al-Himyari, Kitâb ar-Raw ḍ al-Mi'tär, ed. de Lévi-Provençal, Leiden, 1938, página 103 texto árabe y 126 traducción.

so Sobre Ibn Hafağa, véase S. I. Brockleman, Geschichte der Arabischen Literatur, Leiden, 1943, I, pág. 272.

31 Libre del Repartiment, II, pág. 1041. Las alquerías de Alcanissia y Benilacruçi debieron de ser lugares poblados de mozárabes.

32 Cfr. L. Peñarroja, Moriscos cit. II, doc. 8, asiento 204: «[...] te un camp de dos fanecades en la partida de Alquenicia [...]».

33 El documento ha sido publicado por Roque Chabás, Episcopologio I 297, J. Sanchis Sivera, La Diócesis Valentina II, 38; y R. Menéndez Pidal, Revista de Filologia Española 5, 1918, págs. 11-13 y España del Cid, Madrid [7."], 1969, págs. 868-871. Antes por Berganza, Antigüedades de Castilla, I, pág. 463, II, pág. 673, y por Risco, La Castilla y el más famoso castellano, X. 
néndez Pidal en $1918^{34}$ ) estas villas con la alquería de Alcanicia de Alcira : no parece permitirlo la sintaxis del documento ${ }^{35}$ ni es lo que se deduce del sentido geográfico (Sur a Norte) dado por su redactor ${ }^{36}$. Villas de Alcanitja habrán de ser alquerías (aparentemente cercanas a Valencia) donde subsistían población y culto cristianos.

10. Aún en territorio portugués, un presbítero Sahadon y Nazarí figuran como testigos en el testamento del conde mozárabe Exeminus [año 938], el cual lega al monasterio de Lorván, cerca de Coímbra, varias donaciones: una de ellas se sitúa "de parte Alquinitia", esto es, 'de la parte de la iglesia' ${ }^{37}$.

\section{Espigueo en las fuentes ÁRABEs}

Pero interesa más espigar las citas de / kanisa/ en las fuentes hispanoárabes y en los textos árabes relativos a la España Cristiana o Musulmana para probar el fundamental sentido 'iglesia' que ahora trata de negarse.

11.1. Al-'Uḍri [ $†$ 1085] da noticia de cierta mártir cristiana cuyos restos se hallan en una $>$ kanisa $<$ próxima a Cartagena ${ }^{38}$. La misma noticia recoge Al-Himyari (infra). A otra/kanisa/ cercana a Lorca se la relaciona

34 «Las villas de Alcanicia deben ser una alquería de Alcanicia, que había en término de Alcira. Más difícilmente creo - por hallarse nucho más lejos al Sur- que pudiera tratarse del despoblado de Alcanecia, en el Valle de Perpunchent [...] de ningún modo debe pensarse en el Alcañiz de la provincia de Teruel», RFE, 1918, pág. 8.

$35 \mathrm{He}$ cotejado el original (Archivo de la Catedral de Salamanca, Caja 43, legajo 2 , n..$^{\circ}$, ahora exhibido en una de las vitrinas del Museo Catedralicio de la misma ciudad) en copia a tamaño real, gracias a la diligencia del archivero D. Florencio Marcos: «[...] Ego Rudericus Campidoctor et principes ac populos quos Deus quandiu ei placuerit mee potestati commisit, donamus ipsi Redemptori nostro [...] et venerabili pastori nostro Ieronymo pontifici, villam que dicitur Pigacen, cum villis et terris et vineis cultis vel incultis [...] Similiter quoque villas de Alcanitja omnes, cum molendinis et aqueductibus et cum cunctis sibi pertinentibus. Munitionem etiam quam dicunt almunia de Sabaleckem [...] Donamus quoque prescripte sedi atque pontifici aliam almuniam que est iuxta ecclesiam Beate Marie extra murum prefate urbis [...]».

36 El orden de las donaciones va inequívocamente en dirección Norte, a saber: 1) Picassent; 2) villas de Alcanicia; 3) almunia de Sabaleckem, que sin duda se hallaba en la misma Valencia; 4) almunia contigua a la iglesia mozárabe de Santa María extramuros de Valencia; 5) Cebolla ( $<$ árabe /ğuballa/ 'montículo'), hoy El Puig o Santa María del Puig, al norte de Valencia; 6), Farnals (hoy Puebla de Farnals, contigua a Guballa y ligeramente al N., pero citada después, por ser de menor entidad, y dependencia de aquélla); 7) Murviedro (Sagunto); 8) Almenara; 9) Burriana.

37 Archivo da Torre do Tombo, Liber Testamentorum del Monasterio de Lorvāo [Cartulario copiado en el s. XII], doc. 33, fol. 22.

38 Al-'Ud̦rī, Nusuiss an-al-Andalus, trad. parcial de Luis Molina, La cora de Tudmìr en la obra dé Al-'Ud̆ri, Cuadernos de Historia del Islam 3, Granada, 1972, pág. 64. 
con un olivo prodigioso que florecía la primera tarde de mayo ${ }^{39}$. Se trata de la iglesia de Mirabit ${ }^{40}$. Y él mismo inserta una carta del Papa Juan XII, llamado /malik al-rūm bi-Rūmya/ 'el rey de los cristianos de Roma' recabando las reliquias de la iglesia citada $^{41}$, con otras tantas menciones $/ \mathrm{kanisa} /$.

11.2. En Al-Bakrī [† 1094] hay noticia de la /kanisa/ de Sta. María de Gracia, en Carcasona ${ }^{42}$. Santiago es la ciudad de la "iglesia del oro": $>$ kanisa al-d(a)h(a)b $<{ }^{43}$. Al-Idrīsi habla de la /kanisa/ de Santiago y de la / kanisa/ de Santiago y de Sta. Juliana ${ }^{44}$; y de la /kanīsat al-ḡurab/ esto es, de la 'iglesia del cuervo', en el Cabo de San Vicente de Portugal ${ }^{45}$. La misma iglesia comparece en el texto de $\mathrm{Al}$-Himyarī ${ }^{46}$, quien se refiere además a otras tantas /kanīsa/: iglesias en Córdoba ${ }^{47}$; en Mérida ${ }^{48}$; en Santiago de Compostela o Sant Yaqūb ${ }^{49}$ [3 veces] ; y una iglesia de $>$ Sant Bịtr < (San Pedro) en Cádiz ${ }^{50}$. Lugo "está cerca de la iglesia venerada por los cristianos y que ellos llaman Sant Yaqūb" 51. Cerca de Mértola, en Portugal, se alzaha — dice el mismo Himyarī- una $>$ kanisat al-malik $<$ o 'iglesia del rey' ${ }^{52}$. Otras tantas en Toledo ${ }^{53}$, en Carcasona ${ }^{54}$, o en Abaruña, cerca de Calatayud, "una maravilla de construcción que tiene 300 puertas" 55.

39 «Durante la oración de la tarde del día que precedía a la primera noche del mes de mayo, florecía el olivo, y siendo todavía de noche, antes de que amaneciera, los frutos habían cuajado. A la mañana siguiente toda la oliva había ennegrecido, había madurado su fruto y alcanzado su punto de sazón. Ls gentes tuvieron conocimiento de aquello y fueron a verlo. Los emires enviaron a gentes expertas en aquella cuestión para comprobarlo. Los habitantes de aquella comarca cortaron el olivo; y cortado permaneció durante algún tiempo. A pesar de esto volvió a crecer, permaneciendo hasta hoy en el estado ya descrito». Cfr. L. Molina, ibid.

40 La cita de Al-Himyari se atribuye en cambio a la iglesia de $>$ Hisn Sarnìt $<$ o castillo de Sarnit, que no identifica Lévi-Provençal. Cfr. además M.* J. Jiménez Mata, «A propósito del 'aya'ib del olivo maravilloso y su versión cristiana en el milagro de San Torcuato», Cuadernos de Historia del Islam, Granada, 1971, págs. 97-108. La misma narración en Al-Qazwinī, Ațār al-bilād, ed. de Wünstenfeld, Göttingen, 1848, I, pág. 193; y Al-Maqqari, Nafh al-tib min gusn al-Andalus, ed. Dozy Analectes, Leiden, 1865-71, I, pág. 25.

${ }^{41}$ La carta procede de Ibrähim b. by Yaqûb al-Işra'ili al-Ṭurıusíi. Cfr. Molina, ibid., § 17 , pág. 67.

42 Al-Bakrī, Gugrafiyat al-Andalus wa ūrübbã min Kitäb al-Masalik wa-l-mamälik. Ed. de 'Abd al-'Aziz al-Hağğì, Beirut, Dar al-Israd, 1968, pág. 60.

43 Ibid., pág. 61.

44 Al-Idrisī, Nuzhat al-muštăq. Ed. de Saavedra, pág. 62 texto árabe / 63 trad.

45 Ed. de Dozy-Goeje, Leiden, 1866, pág. 173 y 180 texto árabe.

46 Kitâb ar-Rawd, ed. Lévi-Provençal, pág. 2 texto árabe.

47 Ibid., pág. 84 ár. / 104 trad.

48 Ibid., pág. $177 / 213$.

49 Ibid., pág. 155/141.

so Ibid., pág. 145/173. Sobre otras tantas iglesias de Mérida al ocurrir la invasión musulmana, pág. $177 / 212$.

B1 Ibid., pág. 185/213.

52 Ibid., pág. 191/232. 
11.3. El oriental Yãqūt menciona en su $M u^{\prime}$ ğam al-buldān la iglesia de los cuervos ${ }^{56}$, que recogen la mayor parte de Geografias; y habla además de la de Santa Maria de Oriente (/al-Sark/) o Albarracín ${ }^{57}$. El anónimo autor del Dikr bilâd al-Andalus alude por su parte a la iglesia de San Pedro de Cádiz, /kanisa/ "muy venerada por los cristianos" ( $>$ nasārà $<=$ 'mozárabes') ${ }^{58}$; y a la que les fue comprada en Córdoba por 'Abd al-Raḥman al-Ḥadil para engrandecer la mezquita [año 785] ${ }^{59}$. En la misma Córdoba los musulmanes llamaban / kanīsat al-ḥarqà/ 'iglesia de los quemados' o /al-āsrà/ 'de los prisioneros' a una iglesia que había en el barrio de AlRaqqāqin ('de los pergamineros') ${ }^{60}$.

11.4. La equivalencia $>$ kanīsa $<=$ 'iglesia' es, en fin, evidente en los documentos de mozárabes toledanos, muy numerosos, publicados por González Palencia y J. Pons Boigues ${ }^{61}$. De entre las /kanīsa/ de la ciudad de Toledo se citan en ellos las de San Marcos, San Servando, Sta. Colomba, S. Román, S. Sebastián, S. Vicente, S. Zoel, S. Andrés, S. Cebrián, S. Clemente, S. Cristóbal, S. Isidoro, S. Justo, Sanctorum, S. Lorenzo, S. Nicolás, S. Miguel, S. Martín, Sta. María de Talavera, Sta. Eulalia, Sta. Leocadia, Sta. Maria Magdalena y Santiago ${ }^{62}$.

\section{Dos CONCLUSIONES}

12. Si el sentido fundamental de / kanīsa/ y de sus derivados no fuera en nuestros textos el propuesto, habría que preguntarse por qué sus autores

53 Ibid., pág. 191/232.

54 Ibid., pág. 246/247.

ss Ibid., pág. 76/96.

56 Yãqūt, Mu'ğam al-buldân. Ed. Wünstenfeld, Leipzig, 1866-72, I, págs. 375-78.

57 Ibid. III, pág. 215.

$58 \mathrm{Ha}$ sido editado y traducido por Luis Molina, Una descripción anónima de al. Andalus, Madrid, 1983, § 57.

59 Ibid., § 29.

${ }^{60}$ Apud Torres Balbás, loc. cit., pág. 177. Hay referencia a otras iglesias cordobesas, que soslayo.

61 Angel González Palencia, Los mozárabes de Taledo en los siglos XII y XIII, 4 vols., Madrid, 1926-1930; y J. Pons Boigues, Apuntes sobre las escrituras mozárabes toledanas que se conservan en el Archivo Histórico Nacional, Madrid, 1897.

62 Para San Marcos, cfr. González Palencia, doc. 170' San Servando: ibid., 143, $179^{\circ}$; Sta. Colomba: $158^{\circ}, 1.151^{\circ}$; S. Román: $169^{\circ}, 1.031^{\circ}$; S. Sebastián: $1.162^{\circ}$; S. Vicente: $1.152^{\circ}, 1.164^{\circ}, 1.165^{\circ} 1.166^{\circ}, 1.168^{\circ}, 1.172^{\circ}$; S. Zoel: $1.016^{\circ}$; S. Andrés: págs. 83 , 173; S. Cebrián: $34^{\circ}$; S. Clemente: $122^{\circ}, 124^{\circ}, 1.168^{\circ}$; S. Cristóbal: $1.164^{\circ}$; S. Isidoro: $1.169^{\circ}$; S. Justo: $1.169^{\circ}$; Sanctorum: $168^{\circ}, 1.183^{\circ}$; S. Lorenzo: $1.165^{\circ}, 1.172^{\circ}$; S. Nicolás: $1.164^{\circ}$; S. Miguel: $1.168^{\circ}$; S. Martín: $170^{\circ}$; Sta. Marla de Talavera: $141^{\circ}$, $1.178^{\circ}$; Sta. Eulalia: $1.157^{\circ}, 1.158^{\circ}, 1.164^{\circ}$; Sta. Leocadia: $1.157^{\circ}$; Sta. María Magdalena: $1.168^{\circ}$; Santiago: $48^{\circ}, 101^{\circ}, 353^{\circ}, 406^{\circ}, 765^{\circ}, 1.168^{\circ}, 1.185^{\circ}$. 
no hicieron uso de otros tantos términos posibles; y por qué, en todas las citas espigadlas, es precisamente 'iglesia' y no otro, el sentido del arabismo.

Queda decir que la documentación latina alude con frecuencia a las ecclesias mozárabes situadas en los territorios hispánicos no reconquistados: en Córcloba, en Sanlúcar la Mayor, Murcia, Valencia, Denia, Orihuela, Alagún, Valtierra, Cadreita, Murillo de Limas, Tudela, Daroca, Zaragoza, Albarracín, Huesca, Lérida, Tortosa, Aguinalíu, Salou, Amposta, etc. Lo que sugiere no buscar otros sentidos a los pasajes árabes.

En resumen: 1) los topónimos hispanos continuadores de / kanīsa/ evocan, como siempre pensamos, primitivas iglesias cristianas en territorio musulmán; y 2) la mayor extensión semántica de /kanīsa/ en textos no relativos a la Península Hispánica ${ }^{63}$ no es, en ningún caso, criterio de negación del mozarabismo.

63 Lo que no quita la pertinaz referencia 'iglesia' en tales textos árabcs: ya dos documentos en papiro del año 707 mencionan la iglesia de un monasterio egipcio como /Kanisat Mārya/ 'iglesia de María' (Papyri Schott-Reinbardt, I, ed. de C. H. Becker, Heidelberg, 1906, pág. 111, línea 4; pág. 112, línea 4). 